\title{
Semiotic Design of a Hypermedia for Cultural Heritage
}

\author{
Vito Roberto $^{1,2}$ and Elio Toppano ${ }^{1}$ \\ 1 Dipartimento di Matematica e Informatica \\ 2 Norbert Wiener Center \\ University of Udine, Italy \\ \{vito.roberto, elio.toppano\}@dimi.uniud.it
}

\begin{abstract}
The paper proposes a semiotic model inspired to the narrative, structural framework by A.J.Greimas, and applied to the design and analysis of a hypermedia. The framework is structured into four levels of signification and allows for a constructive process of semantic aggregation. We follow such a process in order to explore the conceptual organization of the model. We construct a hypermedia regarding a collection of ancient mosaics from a roman villa. Our results indicate that the proposed approach opens novel perspectives, and looks promising towards the definition of semiotic methodologies of hypermedia design.
\end{abstract}

Keywords: Semiotic, Design, Analysis, Hypermedia, Cultural, Heritage.

\section{Introduction and Related Work}

We address the issue of hypermedia design adopting a semiotic approach, with the aim of exploring its opportunities, and getting insights into possible advantages and limitations. Semiotics is a generic name for a set of disciplines that study the signs, the signification and sense-making processes, and the ways signs and signification take part in communication. Therefore, the focus is on how semantics is originated and can be assigned to the hypermedia, which will be regarded as a generic text - we shall use the terms 'hypermedia' and 'text' as synonyms throughout the paper - to which sense is given according to a constructive process. We adopt the semio-structural model by Greimas 7], 9] and follow the so-called Generative Trajectory of Meaning, which we shall detail and apply in the sequel. Using a plain language is a primary concern of the present paper: terms and techniques borrowed from Semiotics have been introduced and clarified. In order to provide our research with an experimental testbed, we designed and realized a hypermedia for education and entertainment. The aim is presenting a collection of ancient mosaics from the excavations of a roman villa near the city of Trieste, Italy.

Semiotics has slowly gained popularity in Computer Science during the last decade, in different domains of application. Semiotic Engineering is aimed at interpreting Human-Computer Interaction (HCI). Nadin 12 has analyzed computer interfaces; De Souza [15] has argued that Semiotics provides general and

P. Foggia, C. Sansone, and M. Vento (Eds.): ICIAP 2009, LNCS 5716, pp. 425 433, 2009.

(C) Springer-Verlag Berlin Heidelberg 2009 
motivated formulations of the interface guidelines. Nake 13] has mainly worked in the Interactive Graphics and given contributions to Computer Art. Andersen [1] has proposed a systematic analysis of interfaces as sign-complexes. In the field of Communication and Media theory, Semiotics has been used for analyzing new media and websites [3. In the field of hypermedia design, attention has been devoted mainly on modelling global and local discourse coherence [1].

The paper is organized as follows. Section 2 introduces the main features of the framework adopted; the following Section details a process to construct a meaningful text; Section 4 applies the framework to the design of the hypermedia. Our conclusions are in Section 5 .

\section{The Semio-Narrative Framework}

A narrative approach. Ever since a young age humans are exposed to narratives as a form of knowledge transfer. Therefore, narratives are perceived as natural and effective. The semiotician Roland Barthes (quoted in [2]) maintains that narrative is trans-cultural, trans-historical, trans-linguistic. It is suitable to be transposed from a dynamic medium to another, which makes narrative unique among the representation modalities. By narrating we impose an order; we transform a set of unstructured incidents into a sequence of continuous, closed and coherent events [14].

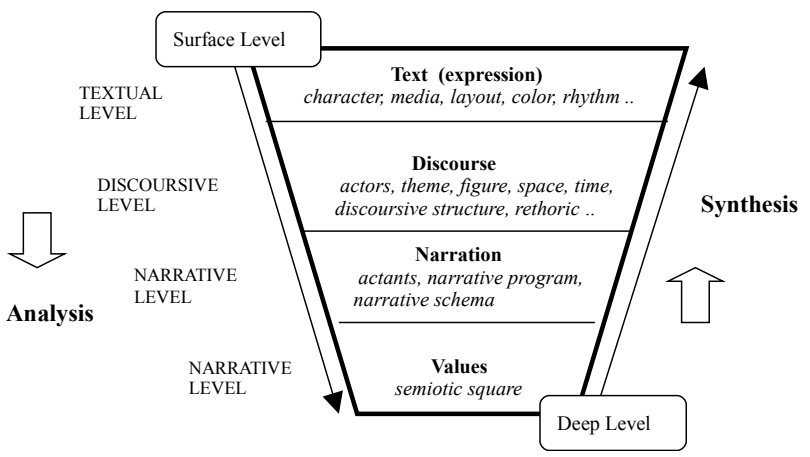

Fig. 1. A graphical scheme of the narrative-structural framework by Greimas

A structural approach. Greimas developed his theory [] with the aim of analyzing narrative productions. Meaning takes form passing through four levels, as sketched in Figure 1] i) the deep semio-narrative structures, representing the fundamental values to be transferred, arranged into a scheme called the semiotic square; ii) the surface semio-narrative structure, with the conceptualizations describing the actions; iii) the discoursive structure; iv) finally, the textual structure, the level of external manifestation. The framework was originally conceived to clarify the meaning of an existing text - e.g., an advertising - starting from 


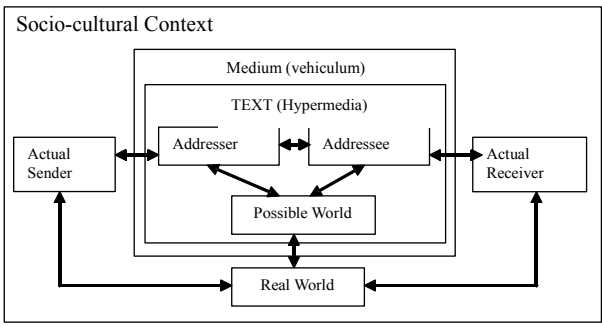

Fig. 2. The communication framework

its external manifestation and proceeding in a top-down fashion across the discoursive and semio-narrative structures. We claim that this view is helpful also for synthesis tasks, to build a meaningful hypermedia by visiting the structure in the opposite direction.

A communication model. Designer and user communicate through the hypermedia within a social and cultural context. Semiotics helps to put forward a thorough model, in which the potential interactions between user and artifact are fully inscribed into the text itself. The scheme in Figure2 generalizes the original model proposed by Jakobson 10 . It considers the actual (empirical) sender (e.g., the designer) and the empirical receiver (the user). They are connected by means of an instrumental medium (vehiculum) - such as a PC connected to a network - which enables the circulation of the text within a socio- cultural context. The text includes two abstract rôles representing the symulacra, i.e., the images reflected onto the text of the empirical sender and receiver, named the addresser and the addressee, respectively. They establish a direct relationship with a possible world, i.e. a narrative universe that reproduces a portion of the real world. In this way, the dialogue between the empirical designer and user, mediated by the text, is inscribed within the text itself.

\section{A Constructive Process of Signification}

The semiotic square. It is the most abstract and elementary structure of signification. It is organized around a basic opposition (contrariety) relation between two conceptual categories, A and B, such as life and death. The square is defined as the logical articulation of this basic opposition; it comprises four terms - A, not-A, B, not-B - connected by three kinds of relations: - Contrariety: the relation between $\mathrm{A}$ and $\mathrm{B}$; not-A and not-B; - Contradiction: between $\mathrm{A}$ and not-A; B and not-B; - Implication or complementarity: between not-B and A; not-A and B. The scheme has been largely used by the semioticians. Floch [5] individuated the basic values associated to a consumer product. Accordingly, there are four kinds of exploitations of an object by a user: practical, critical, ludic and utopic. The first one focusses on utility, effectiveness, usability and reliability of a product; the critical exploitation refers to its efficiency and economic 
convenience; the ludic one is related to the formal qualities, involving aesthetic pleasure and emotions; utopic exploitation refers to existential values, identity and social acknowledgement. We adopted the semiotic square of consumer values for the development of our instructional hypermedia, since it spans all the fundamental values we wish to communicate. We have specialized the terms in the square to the educational context, as shown in Figure 3 .

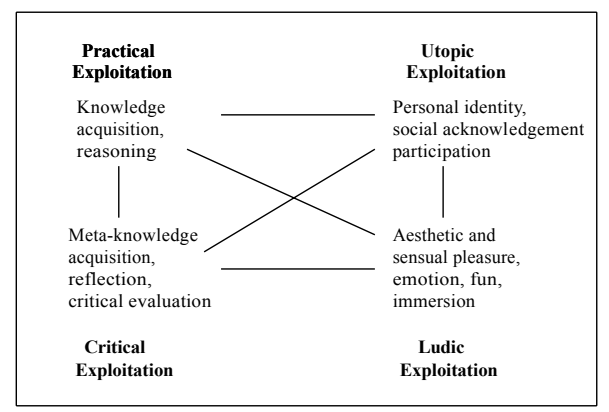

Fig. 3. The semiotic square of an instructional hypermedia

The semio-narrative level. The elements are: Actants (A); Narrative Programs (NP); Narrative Structures (NS) and the Canonical Narrative Scheme (CNS). An actant is something or somebody that acts or undergoes an action. An actant may correspond to an anthropomorphic being, a physical object, or a concept. A narrative program NP is an abstract formula to represent an action (doing), which is a transition between states in order to reach an value object $O_{v}$. The NP's are the building blocks of the narrative structures $N S$. A $N S$ is composed of two or more narrative programs linked by temporal relations succession, simultaneity,...- or logical ones - mutual exclusion, comparison,.... The Canonical Narrative Scheme $C N S$ is a narrative structure including four phases: Manipulation: a sender transmits a message to a receiver/subject, for example the mission to act; Competence: the receiver/subject adheres to the sender's proposal and tries to achieve the resources that are necessary to execute the action;Performance: the subject executes the action and reaches the object of value from whom it was disjuncted; Sanction: the sender evaluates the subject's action, with a reward in case of success or punishment in case of failure. The canonical scheme represents the scaffolding of a narrative at a fully abstract level. The link between the narrative structure and the semiotic square is realized by associating the objects of value $O_{v}$ within each narrative program, to the values $V_{i}$ in the semiotic square.

The discoursive level. Adopts methods borrowed from the Structural Linguistics 4. Each narrative program is mapped onto a discoursive structure, and each of the latter consists of groups of segments in sequential order; each sequence is given its value objective. Converting a narrative structure into a discoursive 
one entails two main processes: the identification of themes and figures, and the realization of the discourse structure. In a given universe of discourse, the figure is an element that evokes sensory perception, while the theme does not. Themes and figures translate the basic constituents of the narration: actants, narrative states and transitions. In this way, an abstract structure is translated into an ordered group of domain concepts - that is, a discourse structure - which is the conceptual organization of a presentation. The structures individuated so far follow a basic sequential order, involving logical and space-time relations. However, the process of sense-making at the discoursive level is to be organized in a more complex fashion. Using rhetorical tropes makes more effective the transmission of contents; naturally, the choice of a trope depends on the contents themselves, and, in turn, influences the design choices at the textual level. Content-based rhetorical relations should be individuated as well.

The textual level. Concerns the perceptual characteristics of the visual and auditory signs used to present the hypermedia content (substance of the expression), as well as the ways signs are related in space and time (form of the expression). Discoursive components such as actors, figurative and thematic elements, rhetorical tropes, are represented by specified media assets. The visual expression can be effectively approached using figurative and plastic semiotics 8 .

\section{A Hypermedia for Ancient Roman Mosaics}

We designed a hypermedia devoted the presentation of a collection of ancient mosaics excavated from a roman villa near the city of Trieste, Italy. The document is addressed to the visitors of the collection, as well as students and teachers willing to learn how a mosaic should be inspected. The semiotic square reported in Figure 3 is the only conceptual scheme supporting the whole document. In Figure 4, $N S_{0}$ has been decomposed into three main substructures: $N S_{1}$, the introduction; $N S_{2}$, the body; $N S_{3}$ the conclusion. The body $N S_{2}$ has been further

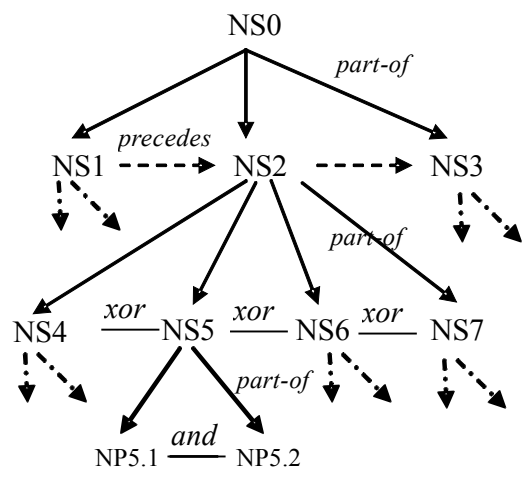

Fig. 4. Narrative structure of the hypermedia. Only the topmost elements have been reported. 
decomposed into four substructures $N S_{4}$ $N S_{7}$ which describe alternative paths within the hypermedia. The leafs of the tree are narrative programs, each one being associated to a single value objective/object.

\subsection{The Catalog of Mosaics}

The catalog of mosaics $(C o M)$ is a tool accessible from all the substructures $N S_{1}, N S_{2}$ and $N S_{3}$. It contains the complete collection of the mosaics (over thirty pieces) in form of cards, with a picture and a short description. The CoM is intended to be a reference to be consulted during the hypermedia navigation. At the narrative level only the abstract action structure of the CoM is relevant. It can be viewed as a dialogue between the tool and the user.

Solutions at the discoursive level. Main themes are: spatial configuration of the mosaics, position, location, order, symmetry,... Figures are the roman villa, the catalogue,... Metaphors are of great help. The catalog itself is a metaphor, which can be enriched with other metaphors: for example, a magnifying glass can be used to signify the relation between two spatial scales. The mise-en-scene is consistent with the metaphors, and is given by a book the user can skim through, in order to acquire the information and the values specified at the level of semiotic square. Moreover, the user can inspect the mosaics at different scales, to single out graphic patterns or constructive details (tesserae).

Textual choices. We used textual media mainly to emphasize practical and critical values (Figure 3): introducing evaluation criteria of mosaics; conveying hystorical background. Instead, static and dynamic images - e.g., 3D animations have been associated to ludic or utopic exploitations: to enhance enjoyment, to to support the user's experience of different space-time dimensions and enhance his/her sense of presence and immersion. Aesthetic (ludic) values are emphasized by letting the user explore the mosaics with a magnifying glass 5 .

\subsection{The Mosaics in Their Placements}

The narrative structure NS5 (Figure 4) is composed by two programs, NP5.1 and NP5.2, linked by a logical AND. The former is associated, in the semiotic square, to a practical exploitation: teaching the user to look at the mosaics within their original locations in the roman villa. The latter program is associated to a utopic exploitation: letting the user make the experience of walking through the rooms of the villa, appreciating the patterns of the mosaics virtually replaced therein. At the discoursive level, the 'mise-en-scene' is the roman villa itself with its external location and internal arrangement of rooms. The helper (an actant) of program NP5.1 has been converted into a museum guide (an actor) providing information and knowledge necessary to achieve the desired practical values. In order to achieve the utopic values, a discourse concerning the space has been devised (trajectory of observation) to let the user relate external with internal spaces. 


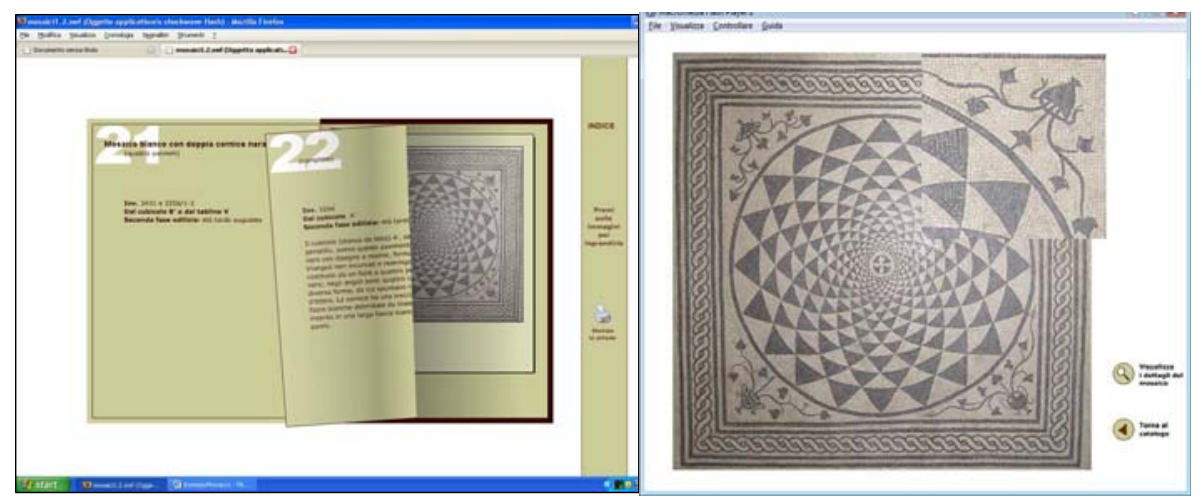

Fig. 5. Two screenshots from the Catalog of Mosaics. Left. The user skims through the pages. Right. The user inspects the mosaic no.22 with the magnifying glass.
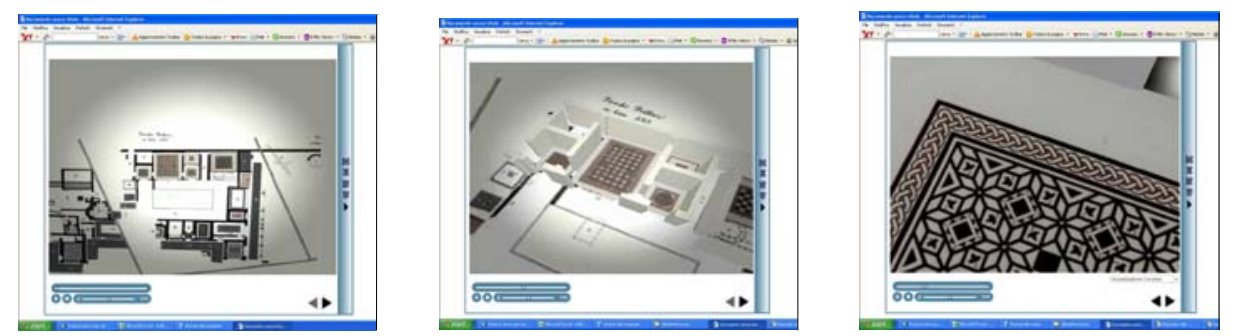

Fig. 6. Three screeenshots from the narrative structure NS5. Left. The planimetry of the roman villa. Middle. The apartments hosting the mosaics. 3D structures are emerging. Right. Moving in a room with a mosaic on the ground.

At the textual level the villa is represented by a 3D graphical model; the museum guide is translated into a narrative voice-over, while the trajectory of observation is realized by a set of camera viewpoints and movements. It starts with an aerial view showing a map (planimetry) of the villa (Figure 6. Left) and continues approaching the apartments hosting the mosaics. During this process, the $2 \mathrm{D}$ planimetry is transformed into a 3D model that gradually rises up (Figure 6. Middle). This corresponds to a transition from a symbolic/abstract representation (the map) to a concrete one (the virtual villa). Then, the camera moves inside the apartments in order to show details of the mosaics just as a 'model observer' would do (Figure 6, Right). In this way, empirical users are encouraged to identify themselves with the 'model observers', and feel like eye-witnesses of the villa reborn. 


\section{Conclusions}

We have explored a semiotic approach to the design of hypermedia, and reported the practical experience of a document concerning a collection of mosaics. We adopted the narrative, structural framework proposed by A.J.Greimas, according to which the semantics is given a structure and assigned by means of a constructive process. We believe that the semiotic approach opens novel perspectives and offers profound, potentially fruitful suggestions. The semantic structure consists of four levels of signification, which are helpful in identifying the main steps of a possible process, and, at the same time, provide a clear-cut organization of concepts, relations and mechanisms to be used by the designer as a reference model. As much as the semiosis itself, semiotic design is likely to be a dynamic, structured and constructive process. It is well known that, in the design of hypermedia, semantic contents are to be kept separate from their expressive forms. However, this principle appears too vague and deserves further specifications. As a matter of fact, the current design methodologies seem to be confined - and constrained - around conceptual structures and their associations to multimedia objects. The semiotic approach allows to gain a deeper insight by adding new signification levels. Two semio-narrative structures support the upper discoursive and textual levels, and help the designer to make explicit the basic principles underlying the document: the profound values to be ultimately communicated, and the abstract narrative scheme to be adopted. We believe it is a substantial step towards the design of 'semantically-rich'- not merely media-rich - documents. Even in the attempt to make objective and reproducible the steps in the design, the model allows for an unlimited freedom in composing the text, and does not constrain to a serial production.

Semiotics is not a monolithic discipline, and several semiotics exist. General Semiotics is a kind of Phylosophy of Language, and Specific Semiotics concern peculiar sign systems, like Text, Music, Advertising, Fashion,... The language of each one tends to be a self-referential jargon, which is still a serious obstacle to the widespread diffusion of semiotic tools. For these reasons, transposing semiotic models into the domains of ICT is still at an exploratory stage, in spite of a few valuable attempts accomplished so far. The same happens for the domain of hypermedia, in which we are far from proposing a true semiotic methodology of design. In this respect, the present paper should be regarded as a further exploration effort. Several semiotic models should be investigated and applied to the hypermedia design, besides - possibly in contrast with - the narrative, structural approach which we propose. A systematic cross-disciplinary effort should be done in this respect. Our research will go further along these directions.

\section{References}

1. Andersen, P.B.: Theory of Computer Semiotics. Cambridge University Press, Cambridge (1997)

2. Chandler, D.: Semiotics for Beginners. e-book (1994), http://www.aber.ac.uk/media/Documents/S4B/semiotic.html 
3. Chandler, D.: Personal Homepages and the Construction of Identities on the Web. In: Aberystwyth Post-Int. Group Conf. on Linking Theory and Practice. University of Wales, Aberystwyth (1998)

4. Fabbri, P., Marrone, G. (a cura di): Semiotica in Nuce. Meltemi, Roma (2000) (in Italian)

5. Floch, J.M.: Semiotics, marketing and communication: Beneath the signs, the strategies. Hampshire, Palgrave (2001)

6. Geurts, J., Bocconi, S., van Ossenbruggen, J., Hardman, J.L.: Towards ontologydriven discourse: from semantic graph to multimedia presentations. In: 2nd Int. Semantic Web Conference (2003)

7. Greimas, A.J., Courtés, J.: Semiotica. Dizionario Ragionato della Teoria del Linguaggio. La Casa Uscher, Firenze (1986) (in Italian)

8. Greimas, A.J.: Semiotica plastica e semiotica figurativa. In: Corrain, L., Valenti, M. (eds.) Leggere l'opera d'arte II. Esculapio, Bologna (1999) (in Italian)

9. Hebert, L.: Tools for text and image analysis: an introduction to Applied Semiotics. E-Book, http://www.revue-texto.net/Parutions/Livres-E/Hebert_AS/ Hebert_Tools.html

10. Jakobson, R.: Saggi di Linguistica Generale. Feltrinelli, Milano (2002) (in Italian)

11. Mancini, C., Buckingham Shum, S.J.: Modelling discourse in contested domains: A semiotic and cognitive framework. International Journal of Human-Computer Studies 64(11), 1154-1171 (2006)

12. Nadin, M.: Interface design: a semiotic paradigm. Semiotica 69, 269-302 (1988)

13. Nake, F.: Human computer interaction: signs and signals interfacing. Languages of Design 2, 193-205

14. Scharfe, H.: Grand Principles of Narratology. In: Bas, I., Freeman, C. (eds.) Challenging the Boundaries, pp. 95-110. Rodopi, Amsterdam (2007)

15. Sieckenius De Souza, C.: The semiotic engineering of Human-Computer Interaction. The MIT Press, Cambridge (2005) 